\title{
A importância do prontuário eletrônico para a perícia médica
}

Introdução: o prontuário eletrônico do paciente (PEP) de forma organizada e concisa possui diversas vantagens, como facilidade de armazenamento, segurança e confiabilidade, com efeitos jurídicos. O objetivo deste trabalho é realizar uma revisão de literatura sobre a importância dos prontuários eletrônicos nos exames periciais. Materiais e Métodos: foram pesquisados artigos nas Bases de Dados: Pubmed, Scielo, Bireme, além de livros de Medicina Legal e Legislação aplicada. Resultados: houve poucas publicações relevantes ao tema, sendo encontradas somente 09 referências; o PEP é um dos documentos mais importantes na questão judicial, sendo cada vez mais utilizado pelos profissionais de saúde; o armazenamento de documentos do PEP em suporte digital apresenta um nível de segurança maior em seus dados. Discussão: é fundamental que o prontuário eletrônico esteja completo, pois, se estiver incompleto, ilegível ou não existir, o médico legista não poderá utilizar essas informações para fundamentar o laudo pericial. Dessa forma, as Instituições de Saúde têm por dever a manutenção do prontuário atualizado e sob sua guarda, pronto a qualquer momento para consulta, ou por intermédio de pleito judicial ser enviada a cópia fiel ao juízo provocado. Conclusão: ainda que o prontuário eletrônico seja um dos principais documentos para a perícia médica, não houve muitas publicações de trabalhos científicos para um estudo mais aprofundado do tema. Porém, ainda assim, foi possível perceber que a sua digitalização trouxe uma maior facilidade de acesso, de armazenamento, e de uma segurança jurídica maior tanto para o médico quanto para o periciado.

Palavras-chave: Prontuário Eletrônico; Prova Pericial; Medicina Legal.

\section{The importance of electronic medical records for medical expertise}

Introduction: the electronic patient record (PEP) in an organized and concise manner has several advantages, such as ease of storage, safety and reliability, with legal effects. The aim of this work is to conduct a literature review on the importance of electronic medical records in expert examinations. Materials and Methods: articles were searched in the Databases: Pubmed, Scielo, Bireme, in addition to books on Legal Medicine and applied legislation. Results: there were few publications relevant to the topic, with only 9 references found; PEP is one of the most important documents in the judicial issue, being increasingly used by health professionals; the storage of PEP documents in digital support presents a higher level of security in your data. Discussion: it is essential that the electronic medical record is complete, because, if it is incomplete, illegible or does not exist, the coroner will not be able to use this information to support the expert report. Thus, the Health Institutions have the duty to keep the medical record updated and in their custody, ready at any time for consultation, or by means of a judicial request, to be sent a copy faithful to the provoked judgment. Conclusion: even though the electronic medical record is one of the main documents for medical expertise, there were not many publications of scientific papers for a more in-depth study of the topic. However, even so, it was possible to perceive that its digitalization brought greater ease of access, storage, and greater legal security for both the physician and the expert.

Keywords: Electronic Health Record; Expert proof; Legal Medicine.

Topic: Ciências Sociais e Humanas em Saúde

Reviewed anonymously in the process of blind peer.
Received: $18 / 10 / 2019$

Approved: 29/01/2020
Yanne Pinheiro de Araújo (iD

Universidade Tiradentes, Brasil

http://lattes.cnpq.br/0441992877690640

http://orcid.org/0000-0001-9322-000X

y araujo@hotmail.com

Halley Ferraro Oliveira

Universidade Tiradentes, Brasil

http://lattes.cnpq.br/3430967306367115

http://orcid.org/0000-0003-0123-7395

halleyoliveira@yahoo.com.br

Brenda Louise Prado Carranza (iD)

Universidade Tiradentes, Brasil

http://lattes.cnpq.br/9920783315388176

http://orcid.org/0000-0002-4756-7974

brendalouise23@gmail.com

\author{
Marina Guimarães Lima (D) \\ Universidade Tiradentes, Brasil \\ http://lattes.cnpq.br/4054706740831421 \\ http://orcid.org/0000-0001-8843-7933 \\ marinalima0347@hotmail.com \\ Renata Calhau Bezerra Chaves \\ Universidade Tiradentes, Brasil \\ http://lattes.cnpq.br/0039482095150891 \\ http://orcid.org/0000-0002-1498-9986 \\ renata calhau@hotmail.com
}

\section{Referencing this:}

ARAÚJO, Y. P.; OLIVEIRA, H. F.; CARRANZA, B. L. P.; LIMA, M. G.;

CHAVES, R. C. B.. A importância do prontuário eletrônico para a perícia médica. Scire Salutis, v.10, n.1, p.18-22, 2020. DOI:

http://doi.org/10.6008/CBPC2236-9600.2020.001.0004

DOI: 10.6008/CBPC2236-9600.2020.001.0004 


\section{INTRODUÇÃO}

O prontuário médico consiste em um acervo documental do paciente, que deve ser registrado pelo profissional, de forma organizada e concisa. Nele devem conter informações completas do paciente atendido, os procedimentos médicos realizados, assim como exames e quaisquer documentos pertinentes a essa assistência (PRESTES JÚNIOR et al., 2017). Esses documentos são de fundamental importância nos exames periciais em vítimas de lesões corporais, visto que, muitas vezes, necessitam de hospitalização antes de realizar a perícia. A análise dos prontuários subsidia, nesses casos, a avaliação do dano ou sequela das lesões encontradas.

Dessa forma, o prontuário eletrônico do paciente (PEP), é a forma ideal de modelo documental de registros médicos, pela facilidade de armazenamento, legibilidade, segurança. É considerado um documento complexo e multidisciplinar, podendo preenchê-lo médicos, enfermeiros e outros profissionais da saúde. Embora seja pertencente ao paciente, é de responsabilidade do médico e das instituições de saúde a sua guarda. Nele armazenam-se o histórico pessoal, patológico e familiar do paciente, somado a receitas médicas, condutas clínicas, bem como a sua evolução. Porém, constitui-se não apenas no registro da anamnese do paciente, mas em todo o acervo documental padronizado, organizado e conciso, referente ao registro dos cuidados médicos prestados, assim como dos documentos pertinentes a essa assistência.

Entretanto, mesmo sendo um documento criado para interesses médicos, o prontuário pode produzir efeitos jurídicos de grande significação médico-legal (FRANÇA, 2014). Nesse sentido, o prontuário não pode ser negado ao paciente, quando solicitado por escrito, para atender ordem judicial ou para a sua própria defesa. Essa obrigatoriedade está descrita no Código de Ética Médica, em 2018 (CFM, 2019). Nesses casos, a cópia do prontuário não caracteriza a quebra de sigilo de informações, já que seria utilizado em benefício do paciente (TONELO et al, 2013). O objetivo do trabalho, portanto, é realizar uma revisão de literatura sobre a importância do prontuário eletrônico nos exames periciais, tendo em vista o fato de que é de interesse médico e do paciente comprovar a veracidade da execução profissional no que se refere à ética médica.

\section{METODOLOGIA}

Foi realizada uma revisão de literatura, de caráter descritivo-discursivo, onde foram pesquisados artigos em diversas Bases de Dados, como Pubmed, Scielo, Medline, além de livros de Medicina Legal e Legislação aplicada. A busca teve como critérios de inclusão: língua portuguesa, espanhola e inglesa. Como critério de exclusão, foram descartados artigos com período inferior a 2014 e legislação vigente. Para os resultados da pesquisa, foram utilizados os termos: prontuário eletrônico, registro eletrônico, prontuário médico, prontuário eletrônico e perícia, relação do prontuário eletrônico com a perícia médica e prontuário eletrônico e efeitos jurídicos.

Ao primeiro resultado das pesquisas, foram encontrados 17.318 trabalhos nos bancos de dados. Porém, ao serem excluídos teses, dissertações, monografia e o período inferior a 2014, restaram 37 
resultados, cujos textos eram completos e em PDF. Destes, foram destacados com importância para este artigo apenas 04 .

Também foram pesquisados livros e legislações referentes ao tema, sendo encontrados 02 livros, 02 resoluções do Conselho Federal de Medicina (CFM) e 01 Cartilha do CFM. Ou seja, 09 referências pertinentes ao tema foram encontradas. Vale ressaltar que quando se filtra os resultados para dados especializados e revisões sistemáticas atualizadas, não foram encontrados resultados na busca. Deste modo, foram selecionados os artigos cujos conteúdos continham as melhores relevâncias para corresponderem ao tema proposto.

\section{DISCUSSÃO TEÓRICA}

Com o estudo destes trabalhos, foi possível perceber que o Prontuário Eletrônico é um documento relevante na questão judicial, pois ele é avaliado minuciosamente por peritos e, a partir dele, ocorrem as decisões judiciais. Somado a isso, foi visto também que ele vem sendo cada vez mais utilizado pelos profissionais de saúde, devido a sua tamanha importância, qualidade e facilidade na busca do histórico do paciente, visto que, "os dados armazenados são mais legíveis, exatos e confiáveis; e as ferramentas que acompanham o PEP reduzem a possibilidade de erro" (CÂNEO et al., 2014).

Ademais, o seu armazenamento de documento em suporte digital, apresenta um nível de segurança maior de seus dados, já que, segundo a Sociedade Brasileira de Informática em Saúde (SBIS) e o Conselho Federal de Medicina (CFM), o Prontuário Eletrônico do Paciente deve possuir requisitos mínimos e obrigatórios em vários aspectos e, em nível de segurança, devem abranger o Nível de Garantia de Segurança 1 (NGS1), cumprindo uma série de requisitos de segurança, tais como o controle da versão do software utilizado, controle de acesso, disponibilidade, autenticação, comunicação remota, auditoria e documentação, e em um nível mais elevado de segurança, o NGS2, deve cumprir todos os requisitos já dispostos no primeiro nível, acrescentando a utilização de certificados digitais Infraestrutura de Chaves públicas Brasileira (ICP-Brasil) nos processos de assinatura e autenticação (BORROZINO et al., 2015).

Nos artigos encontrados foi possível evidenciar que o prontuário médico eletrônico serve como prova, podendo ser utilizado com finalidade jurídica ou pericial, principalmente nos casos onde houve um razoável decurso de tempo entre a ocorrência do fato e o exame pericial. De acordo com a Resolução CFM no 1.638/2002, o prontuário médico, independentemente de ser eletrônico ou em papel, é definido como um documento único constituído de um conjunto de informações, sinais e imagens registradas, geradas a partir de fatos, acontecimentos e situações sobre a saúde do paciente e a assistência a ele prestada (CFM, 2002).

Corroborando com o tema, França (2019) entende que o prontuário médico, além da anamnese, possui todo acervo documental padronizado, conciso e ordenado dos cuidados médicos prestados. Assim sendo, diante do número de informações do paciente, o prontuário se torna de grande valia para investigações criminais e até mesmo como único meio de prova, sendo indispensável para apuração dos fatos o acesso ao documento médico nos autos do inquérito policial. 
O prontuário tradicional apresenta diversas limitações, sendo ineficiente para o armazenamento e organização de grande volume de dados, apresentando diversas desvantagens em relação ao prontuário eletrônico. A informação do prontuário em papel está disponível somente a um profissional ao mesmo tempo, possui baixa mobilidade e está sujeito a ilegibilidade, ambiguidade, adulteração, perda frequente da informação, multiplicidade de pastas, dificuldade de pesquisa coletiva, falta de padronização, dificuldade de acesso, fragilidade do papel e a sua guarda requer amplos espaços nos serviços de arquivamento (FRANÇA, 2019).

De acordo com este autor, vários estudos ao redor do mundo têm demonstrado o impacto positivo em que a implementação de um PEP pode trazer, inclusive como meio de prova documental mais seguro e com menor risco de adulterações nas perícias médicas de lesão corporal, onde o periciado esteve sob internação hospitalar ou procedimento cirúrgico, e precisou realizar exame pericial no Instituto Médico Legal. Dados confiáveis de um PEP auxiliam na avaliação dos danos e das sequelas corporais decorrentes de lesões acidentais ou mediante violência (FRANÇA, 2019).

O acesso ao prontuário médico em caso de perícias médicas pode ser solicitado por terceiros, quando autorizado por escrito, pelo paciente, para atender ordem judicial ou para a própria defesa do médico, conforme os artigos 88 e 89 do Código de Ética Médica (CFM, 2019). É mister sempre assegurar-se de que o prontuário eletrônico esteja completo, pois, em uma perícia de lesão corporal de natureza cível ou criminal, se o prontuário estiver incompleto, ilegível ou não existir, o médico legista não poderá utilizar essas informações para fundamentar o laudo pericial.

Por essa razão, as Instituições de Saúde têm por dever a manutenção do prontuário atualizado e sob sua guarda, pronto a qualquer momento para consulta, ou por intermédio de pleito judicial ser enviada a cópia fiel ao juízo provocado, servindo como elemento indispensável da prova pericial. Com isso, a função da equipe de saúde é atuada por meio do conteúdo contido dentro do prontuário, a qual deve ser indubitavelmente regida por princípios éticos, com a execução da medicina legal pelos profissionais de saúde.

\section{CONCLUSÕES}

Nesse sentido, entende-se que a importância do prontuário eletrônico do paciente frente à perícia médica, reside na maior facilidade e qualidade de acesso documental, somado ao fato de que a sua digitalização trouxe uma segurança jurídica maior tanto para o médico quanto para o lesado. 0 prontuário eletrônico representa uma maior proteção contra fraude devido a maior dificuldade de adulteração dos seus dados, depois que o documento é liberado pelo sistema. Porém, para que haja êxito na utilização do prontuário eletrônico em situações periciais, é necessário que haja um correto preenchimento. Salientando que, apesar da sua importância, deve-se evitar realizar uma perícia somente com dados provenientes de prontuários, utilizando-o como auxílio na avaliação e caracterização das lesões corporais ou das suas sequelas. Ademais, é mister que, a curto, médio e longo prazo haja mais pesquisas para um melhor aprofundamento do tema, e, consequentemente, ratificação dos dados obtidos. 


\section{REFERÊNCIAS}

BORROZINO, F. N.; PIZ, T. I.. Aspectos legais do Prontuário Eletrônico do Paciente: um Comparativo do Cenário atual frente a Resolução do CFM. Ciência et Praxis, Belo Horizonte, v.8, n.15, p.23-27, 2015.

CÂNEO, K. P; RONDINA, M. J.. Prontuário Eletrônico do Paciente: conhecendo as experiências de sua implantação. Journal of Health Informatics, São Paulo, v.2, n.2, p.67-71, 2014.

CFM. Conselho Federal de Medicina. Código de Ética Médica: Resolução CFM no 2.217, de 27 de setembro de 2018, modificada pelas Resoluções CFM no 2.222/2018 e 2.226/2019. Brasília: Conselho Federal de Medicina, 2019.

CFM. Conselho Federal de Medicina. Resolução CFM no 1.638/2002. Define prontuário médico e torna obrigatória a criação da Comissão de Revisão de Prontuários nas instituições de saúde. Brasília: Conselho Federal de
Medicina, 2002.

FRANÇA, G. V.. Fundamentos de Medicina Legal. 10 ed. Rio de Janeiro: Guanabara Koogan, 2014.

FRANÇA, G. V.. Comentários ao Código de Ética Médica. 7 ed. Rio de Janeiro: Guanabara Koogan, 2019.

PRESTES JÚNIOR, L. C.; RANGEL, M.. Prontuário médico e suas implicações médico-legais na rotina do coloproctologista. Rev. Bras. Coloproctol., Rio de Janeiro, v.27, n.2, p.154-157, 2017. DOI: http://dx.doi.org/10.1590/S0101$\underline{98802007000200004}$

TONELLO, I. M. S.; NUNES, R. M. S.; PANARO A. P..

Prontuário do paciente: a questão do sigilo e a lei de acesso à informação. Rev. Informação \& Informação, Londrina, v.18, n.2, p.193-210, 2013.

A CBPC - Companhia Brasileira de Produção Científica (CNPJ: 11.221.422/0001-03) detém os direitos materiais desta publicação. Os direitos referem-se à publicação do trabalho em qualquer parte do mundo, incluindo os direitos às renovações, expansões e disseminações da contribuição, bem como outros direitos subsidiários. Todos os trabalhos publicados eletronicamente poderão posteriormente ser publicados em coletâneas impressas sob coordenação da Sustenere Publishing, da Companhia Brasileira de Produção Científica e seus parceiros autorizados. Os (as) autores (as) preservam os direitos autorais, mas não tem permissão para a publicação da contribuição em outro meio, impresso ou digital, em português ou em tradução. 